\title{
Intramedullary granuloma suggestive of tuberculoma
}

\author{
Vinicius M. Guirado 1,2, Leonardo C. Welling 1,2, Alexandre Meluzzi ${ }^{1,2}$, Marcelo E. Sette dos Santos², \\ Eberval Gadelha Figueiredo', Mario Augusto Taricco', Manoel Jacobsen Teixeira'
}

Tuberculosis is still a major health problem in many parts of world, especially Asia, Africa and South America. The most common form of spinal intradural tuberculosis is meningitis and intramedullary tuberculomas are rare ${ }^{1}$. According to Citow and Ammirati intramedullary tuberculomas are seen in two of 100000 cases of tuberculosis and in two of 1000 cases of central nervous system tuberculosis $^{2}$. The ratio of intramedullary spinal to intracranial tuberculoma was found to be 1:42 in one major series ${ }^{3}$.

\section{CASE}

A 26-year-old woman presented with two-month back pain followed by paraparesis. At admission unit, the patient presented with urinary retention and paraparesis grade II. Magnetic resonance images demonstrated intramedullary lesion, at C7-T1 level, with ring contrast enhancement (Fig 1A, 1B, 1C), and lytic lesion on T8 vertebral body (Fig 1D). The patient tested negative for HIV. In view of the evidence of tuberculosis by the radiological appearance in T8 level, a presumptive diagnosis of intramedullary tuberculoma was made, and the patient received chemotherapy. However the neurological deficits worsened and the surgery was planned. A laminotomy at C7-T1 level was done followed by debulking of the lesion microsurgically.

Histopathologic examination revealed lymphocytes, epithelioid cells, and Langerhans giant cells indicative of tuberculoma (Fig 1E, 1F). Cultures were negative and PCR has not been done. Postoperatively, patient showed gradual improvement in power over a period of six months.

\section{DISCUSSION}

The common location of intramedullary tuberculoma is the thoracic cord and less commonly in the cervical and lumbar regions. The best imaging modality for diagnosis is magnetic resonance image ${ }^{4}$. The ideal treatment remains controversial, and many authors have recommended medical treatment. Surgery is generally indicated when there is no response to chemotherapy, the diagnosis is in doubt or rapid deterioration in neurolog-

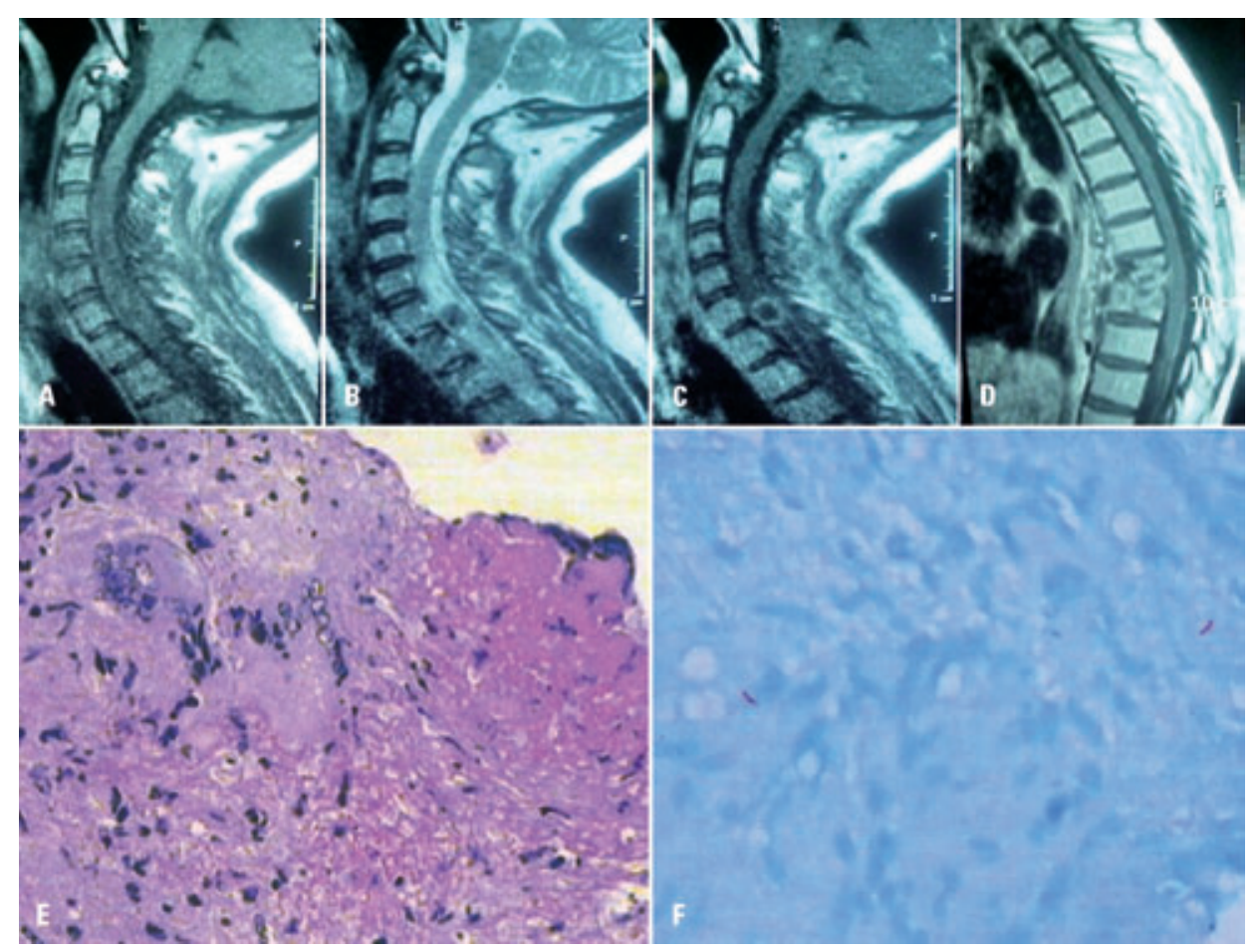

Figure. $[A, B, C]$ Magnetic resonance images: intramedullary lesion with ring contrast enhancement at C7-T1 level; [D] Lytic lesion in T8 certebral body; [E, F] Histhologic examination revealed lymphocytes, epitheliod cells, and Langerhans giant cells indicative of tuberculoma. 
ical function ${ }^{5}$. We recommend that patients who present with advanced neurological deficits should undergo early descompression even with adequate chemotherapy, since the intramedullary location and expansion of the cord with demyelinating destruction of tracts could worsen the clinical status.

\section{REFERENCES}

1. Suzer T, Coskun E, Tahta K, et al. Intramedullary spinal tuberculoma presenting as a conus tumor: a case report and review of the literature. Eur Spine J 1998;7:168-171.

2. Citow JS, Ammirati M. Intramedullary tuberculoma in the spinal cord: case report. Neurosurgery 1994;35:327-330.

3. MacDonell AH, Baird RW, Bronze MS. Intramedullary tuberculomas of the spinal cord: case report and review. Rev Infect Dis 1990;12:432-439.
4. Bansal D, Singhi PD, Ray M, et al. Cervical intramedullary tuberculoma: acute presentation and rapid response to medical therapy. J Trop Pediatr 2002;48:55-57.

5. Devi BI, Chandra S, Mongia S, et al. Spinal intramedullary tuberculoma and abscess: a rare cause of paraparesis. Neuro India 2002;50:494-496.

\section{GRANULOMA INTRAMEDULAR SUGESTIVO DE TUBERCULOMA}

${ }^{1}$ Division of Neurological Surgery. Hospital das Clínicas, University of São Paulo, São Paulo SP, Brazil; '2Division of Neurological Surgery, Hospital Santa Marcelina de Itaquaquecetuba, Itaquaquecetuba SP, Brazil.

Correspondence: Leonardo Welling - Rua Tiradentes 976 / 01 - 84010-190 Ponta Grossa PR - E-mail: leonardowelling@yahoo.com.br

Received 6 March 2011, received in final form 27 June 2011. Accepted 5 July 2011.

\title{
Anchored fat-fascia graft for clival skull base reconstruction
}

\author{
Henrique Faria Ramos' ${ }^{1}$ Carlos Diógenes Pinheiro-Neto', \\ Pedro Paulo Mariani², Fabrizio Ricci Romano ${ }^{1}$, Arthur Cukiert ${ }^{2}$
}

Wound closure after posterior cranial fossa surgery through the clivus remains a challenge. A multilayer closure was suggested by some authors ${ }^{1,2}$. On the other hand, a multilayer reconstruction may not be achieved in patients with clival defects; in this region, gravity may displace the inlay grafts downwards. We developed a technique that allows layered reconstruction of skull base defects, especially those located in the clivus.

\section{CASE}

A 14 years-old male presented with headache and a large craniopharyngioma was diagnosed. The lesion had a solid suprasellar component and a large cyst extending inferiorly towards the atlantoaxialregion, compressing the medulla (Fig 1A).

The patient underwent to surgery through a transesphenoidal endoscopic approach. The bone of the sellar floor, posterior clinoidsand clival recess were widely removed using a high-speed drill (Fig 1B). The dura was then opened, followed by drainage of the craniopharyngioma cyst (Fig 1C and 1D). After the cyst drainage there was intense bleeding from the basilar venous plexus, which was managed using Surgicel ${ }^{\circ}$.

Reconstruction was carried out using a lateral thigh fat graft, with the same shape as the dural defect, but longer. It was anchored with a 4.0 Vicrylsuture. The graft was reinforced with a rectangularlayer of fascia lata, larger than the dural defect. A hole was made in the center of the fascia lata graft, allowing it to be slid up along the suture. The fat graft was pushed intradurally through the defect to pack the tumor cavity and form a buttress for subsequent layers (Fig 1E), followed by the underlay positioning of the fascia lata. The suture was gently tractioned until the fat-fascia graft was pulled beyond the bony margins and sealed the dural defect (Fig 1F). After confirmation of the watertight sealing of the dural defect by a Valsalva maneuver the suture is cut (Fig 1G and $1 \mathrm{H})$. Fibrin glue was then applied and an additional overlay layer of fascia lata was positioned. In addition, the reconstruction was reinforced with a pediculatednasoseptal flap positioned over the margins of the bony defect and Gelfoam. A Folley balloon catheter was left in place supporting the multilayer reconstruction. The patient was discharged on Day 7 postoperatively, with no headache or CSF leak.

\section{DISCUSSION}

Since the introduction of the nasoseptalpedicled flap there has been a sharp decrease in the incidence of postoperative CSF leaks ${ }^{2,4}$. In addition to it, a multilayer reconstruction was adopted by many authors ${ }^{1-4}$, aiming at higher efficacy and reliability in creating a watertight closure.

The anchored fat-fascia graft used in our patient al- 